\title{
A dimensão afetiva na interação plurilingue: Dinâmicas de negociação de imagens e estereótipos na interação romanófona em chat 1
}

\author{
Sílvia Melo-Pfeiferi
}

University of Hamburg, Germany \& CIDTFF da Universidade de Aveiro, Portugal

\section{Maria Helena Araújo e Sáii}

Universidade de Aveiro, Portugal

Resumo

Tendo em conta a relevância da Internet ao nível do contacto intercultural e plurilingue, e definindo-se os espaços de comunicação como lugares de emergência e de negociação de imagens acerca do Outro, analisaremos um corpus constituído por interações plurilingues romanófonas em chat, com vista ao estudo da dinâmica das imagens e estereótipos nessa situação de comunicação. Tentaremos desocultar e analisar barreiras à comunicação intercultural, algumas utopias acerca dela (em particular, o recurso a uma língua franca como solução para os problemas comunicativos) e ainda facilidades propulsoras da interação, como a relação afetiva com as línguas, os locutores e a situação de comunicação. A discussão dos dados permitirá evidenciar como as imagens e os estereótipos cruzados de uns locutores em relação aos outros, às suas línguas e culturas emergem na interação, como estimulam e alimentam a conversação e como desencadeiam momentos "felizes" de comunicação plurilingue.

Palavras-chave

Comunicação eletrónica; Intercompreensão; Imagens; Estereótipos 


\section{Introdução}

Ao longo das últimas décadas, questões relacionadas com a educação para a cidadania, para os valores, para a convivência democrática e para a diversidade linguística e cultural adquiriram um papel de destaque na reflexão em Educação. Na área da Didática de Línguas, em que situamos este estudo, conceitos como competência plurilingue e intercultural e intercompreensão vieram corporizar aquele destaque numa área específica, acentuando a dimensão ética, política e social do conhecimento por ela produzido (Alarcão et al., 2009; Beacco, 2013).

Neste contexto, assumem particular relevância os estudos que tomam a Internet como contexto privilegiado de contacto com a diversidade linguística e cultural e a comunicação online como trunfo potenciador de aquisição de diferentes competências em Línguas Estrangeiras (LE) (referimos, a título de exemplo, os estudos de Melo, 2006; Melo-Pfeifer, \& Araújo e Sá, 2013; Tudini, 2002, 2003). Todavia, os trabalhos que se têm desenvolvido sobre esta forma de comunicação debruçam-se, quase exclusivamente, sobre problemáticas relacionadas com a aquisição de uma LE particular, numa lógica de binómio linguístico, sem dar conta da efervescência linguística que, apesar de presente na Internet ao nível dos sites publicados em LE, não caracteriza o mundo da comunicação eletrónica, marcadamente anglófono (acerca da diversidade linguística na Internet, ver, por exemplo, Pimienta, 2002, e o relatório do Parlamento Europeu, 2000) e monolingue/monoglóssico.

O nosso estudo, situando-se no âmbito da plataforma de comunicação em línguas românicas Galanet ${ }^{2}$, insere-se numa lógica de valorização e desenvolvimento da competência plurilingue em situação de comunicação em chat, mais especificamente através do desenvolvimento da intercompreensão entre locutores de diferentes Línguas Românicas (LR), em que cada locutor pode utilizar, de acordo com as suas vontades, competências e objetivos, a sua Língua Materna (LM) e/ou as línguas dos restantes locutores (Bono \& Melo-Pfeifer, 2011). Trata-se, na realidade, de um entendimento do uso, simultâneo ou alternado, das diferentes línguas, não como sinal de atavismo e de incompetência em alguma(s) dela(s), mas antes como marca de um "parler plurilingue" (Lüdi, 2004) disponível, caracterizado pelo seu carácter flexível e versátil, cujo uso depende dos objetivos comunicativos e da situação 
de comunicação, onde diferentes repertórios linguístico-comunicativos e de aprendizagem (de nível cognitivo-verbal e processual) dos interlocutores se conjugam com uma dimensão afetiva e atitudinal (Araújo e Sá, 2013). Alargase, deste modo, o conceito de "parler bilingue", desenvolvido, nomeadamente, por Lüdi (1987) e Lüdi e Py (1986), e entendido, brevemente, como a passagem de uma(s) língua(s) a outra(s) segundo as situações de comunicação, sabendo que a escolha das línguas "n'est pas arbitraire, mais suit des règles socialement établies" (Py, 1994, p. 75) e que "le choix de langue est négocié entre les partenaires de l'interaction et que la dynamique conversationnelle y joue un rôle indéniable" (Py, 1994, p. 93). Neste sentido, o conceito de "parler plurilingue" é mais lato do que o conceito de "codeswitching", em que a ênfase é colocada na alternância de códigos, para abarcar a mobilização de todos os recursos linguísticos presentes nos repertórios dos falantes, com fins comunicativos, identitários e gregários.

Num primeiro momento, destacaremos, de um ponto de vista teórico, o papel que os estereótipos e as representações podem ter no desenrolar de interações plurilingues e interculturais. Numa segunda fase desta contribuição, explicitaremos algumas das características da interação em chat, para melhor compreendermos o universo discursivo em que ocorrem os "rituais de interação" que observaremos. Finalmente, analisaremos episódios e sequências interacionais em que se manifestam e são negociados representações e estereótipos na comunicação plurilingue em chat, potenciando ou travando a intercompreensão entre os interlocutores romanófonos.

\section{Que lugar para os estereótipos e representações na comunicação plurilingue em chat?}

A diversidade de línguas da Europa e a preocupação com a mobilidade dos seus cidadãos têm sido alguns dos fatores propulsores da definição de políticas europeias, nomeadamente de carácter linguístico, favorecendo o aparecimento de programas como Erasmus, Comenius, Sócrates/LINGUA, numa clara perspetiva de reconhecimento e (re)valorização do património linguístico europeu. A par da definição destas políticas linguísticas e muito impulsionados por elas, ganharam nova relevância, em Didática de Línguas, conceitos como "plurilinguismo", "comunicação intercultural", "identidade 
linguística", "competência plurilingue" e "intercompreensão", conceitos estes que têm vindo a enformar os documentos oficiais de educação em línguas e, assim, a entrar paulatinamente na formação de professores, nas práticas de sala de aula e nos materiais didáticos disponíveis.

No contexto deste trabalho, assume particular importância o conceito de competência plurilingue (CP), entendida como "capacidade para utilizar as línguas para comunicar na interação cultural, na qual o indivíduo, na sua qualidade de actor social, possui proficiência em várias línguas, bem como experiência de várias culturas" (Conselho da Europa, 2001, p. 187). Desta definição, decorre o carácter fortemente pessoal e intransmissível da CP, vista já não como justaposição de competências distintas, mas antes como uma competência complexa e compósita ao serviço das necessidades e objetivos comunicativos de cada falante. Considerando-se também que é constituída por um conjunto de repertórios (afetivos, linguístico-comunicativos e cognitivoverbais - cf. Andrade \& Araújo e Sá, 2003), assume-se que estes não são compartimentos estanques que se desenvolvem e atuam isoladamente, mas antes uma constelação de competências interatuantes.

Situamos o enfoque do presente trabalho na dimensão socioafetiva da interação plurilingue, num contexto particular: a interação em LR em situação de chat. Pensamos que é um contexto particularmente rico de observação e de análise, uma vez que, se entendermos a interação como local privilegiado de observação da CP em ação, enquanto local de inscrição do eu na sua relação com o Outro, de visibilização das suas competências e de um trabalho linguístico colaborativo (que implica o recurso a todos os repertórios disponíveis), então, num chat plurilingue esperamos encontrar exemplos da mobilização de estereótipos e representações, positivos ou negativos, úteis ou prejudiciais, conforme funcionem como motores ou obstáculos comunicativos, respetivamente. Esta hipótese motiva e orienta, com efeito, o presente estudo.

Numa situação comunicativa como esta, as barreiras e utopias em relação ao contacto com a alteridade e à intercompreensão poderão advir da manifestação (verbal ou não) de (des)interesses e (des)motivações em relação à diversidade linguística e cultural, bem como da mobilização de estereótipos e representações acerca dos interlocutores, das línguas e da situação de comunicação. Essas representações e estereótipos, sendo 
inevitáveis e até indispensáveis (cf. Amossy \& Herschberg Pierrot, 1997, p. 43), influenciam a comunicação intercultural e, de certa forma, condicionam o encontro com o diverso, podendo determinar a intercompreensão entre os interlocutores, objetivo comunicativo por excelência, quer se trate ou não de comunicação plurilingue. Nas palavras de Amossy e Herschberg Pierrot (1997), "les représentations stéréotypées de l'Autre traversent inévitablement le vécu de la rencontre" (p. 42) ou, nas de Jodelet (1989), "les représentations sociales, en tant que systèmes d'interprétation, régissent notre relation au monde et aux autres, orientent et organisent les conduites et les communications sociales" (p. 41). Neste sentido, este "déjà-là" pré-existente ao encontro com o Outro influencia o processo e o sucesso do contacto intercultural e, por sua vez, o (in)sucesso desse encontro atenuará ou corroborará as representações iniciais (cf. Oesch-Serra, 1995, acerca da reformulação da perceção do Outro e da evolução dos estereótipos em situação de migração na Suíça).

Tendo em conta que as representações e os estereótipos funcionam como "prêt-à-porter" interpretativos e como instrumentos de manipulação simbólica da realidade (dos fenómenos e dos grupos sociais, dos indivíduos, dos modelos culturais $\left.{ }^{3}, \ldots\right)$, desempenhando uma dupla função cognitiva e social, "l'activation des catégorisations, dont les stéréotypes sont porteurs, influence donc fortement toute communication et gouverne le 'rituel d'interaction' (Goffman, 1974)" (Oesch-Serra, 1995, p. 163).

Tratando-se, como a seguir veremos, de uma situação de interação particularmente exigente, implicando o recurso a competências de dois níveis (o conhecimento e utilização das regras de comunicação em chat, o contacto simultâneo com diferentes línguas e, eventualmente, o recurso a elas), é da movimentação simultânea e eficaz a esses dois níveis que surgirão, na nossa opinião, episódios de "bonheur conversationnel" (Auchlin, 1995) e de intercompreensão entre os chatantes. Estes episódios, para os quais contribuirão as auto e heterorrepresentações e estereótipos dos sujeitos, revelarão, segundo Auchlin (1995), "la qualité de l'accomplissement langagier des interactants" (p. 9), isto é, o cruzamento de interesses, de vontades e de valores dos chatantes, bem como as suas competências discursivas. 


\section{A comunicação em chat: "Nem precisamos de nos ver para nos entendermos, não é?"}

Se entendermos os chats como

conversations virtuelles et non-présentielles, avec un nombre variable d'interlocuteurs, qui affichent des identités plus ou moins cachées et changeantes, et dont la quasi-totale opacité contextuelle favorise les ambiguïtés et les indéterminations au niveau des contextes de production et de réception des échanges (Araújo e Sá \& Melo, 2003a, p. 96),

podemo-nos perguntar como é que os sujeitos comunicam, apesar das limitações do meio e da ausência dos canais visual e auditivo. Todavia, como nota Yus (2001), "muchos usuarios establecen interacciones conversacionales con otras personas no a pesar de, sino precisamente porque el chat posee esa inherente cualidad textual" (p. 88).

$\mathrm{Na}$ verdade, os chatantes improvisam e criam formas/fórmulas alternativas de exprimir o conteúdo verbal, paraverbal e não-verbal das mensagens, utilizando os recursos que o teclado coloca à sua disposição, revelando, desde logo, criatividade a três níveis: (i) em relação ao uso da tecnologia, potenciando o seu uso comunicativo e pragmático (criação e uso de smileys, com finalidades paraverbais, uso de maiúsculas com fins prosódicos, por exemplo); (ii) em relação ao uso da(s) língua(s) de comunicação (escrita fonética, uso de "narração em terceira pessoa", de entre outras); (iii) em relação à forma como esses dois usos são combinados num peculiar "galimatías gráfico" (Morala, 2001), revelador de uma comunid@de linguística com idiossincrasias próprias, em que cada sujeito se apropria livre e criativamente das linguagens disponíveis. Como sintetiza Mayans i Planells (2002), "a través de todos estos recursos, se pretende y consigue . . . agilizar y acelerar el intercambio comunicativo; hacerlo más vivaz y flexible, acercándolo al habla y a diversas jergas o variantes coloquiales; y personalizarlo, individualizarlo, aumentar su potencial expresivo" (p. 86).

Para além destes aspetos, importa referir o carácter polifónico das interações geradas através e pelos chats, resultante da copresença variável de diferentes interlocutores, de diversos espaços geográficos, culturais e temporais: distinguimos as duas matizes (através e pelos) porque, como se sabe, não só os sujeitos coconstroem, simultaneamente, diferentes sequências interacionais, como estas sequências são ainda interpenetradas 
por intervenções do servidor, qual narrador das ações que se desenrolam online. Esta polifonia, no caso dos chats que analisaremos (veja-se a próxima secção para mais detalhes), abrange o uso, pelos diferentes sujeitos, de diferentes LM (as suas e as dos seus interlocutores), revelando uma construção discursiva que reverte dois pressupostos generalizados do que significa uma "comunicação efetiva": o uso de uma língua comum na interação exolingue (aqui plurilingue) e o carácter linear e, por isso, aparentemente mais coeso, das intervenções dos sujeitos. Ora, como a seguir ilustramos, estas supostas regras da comunicação não são observáveis em chats plurilingues, onde a sua aparente transgressão serve como desencadeadora da comunicação (ou "desbloqueadora de conversa") e revela episódios de bemestar comunicacional ${ }^{4}$.

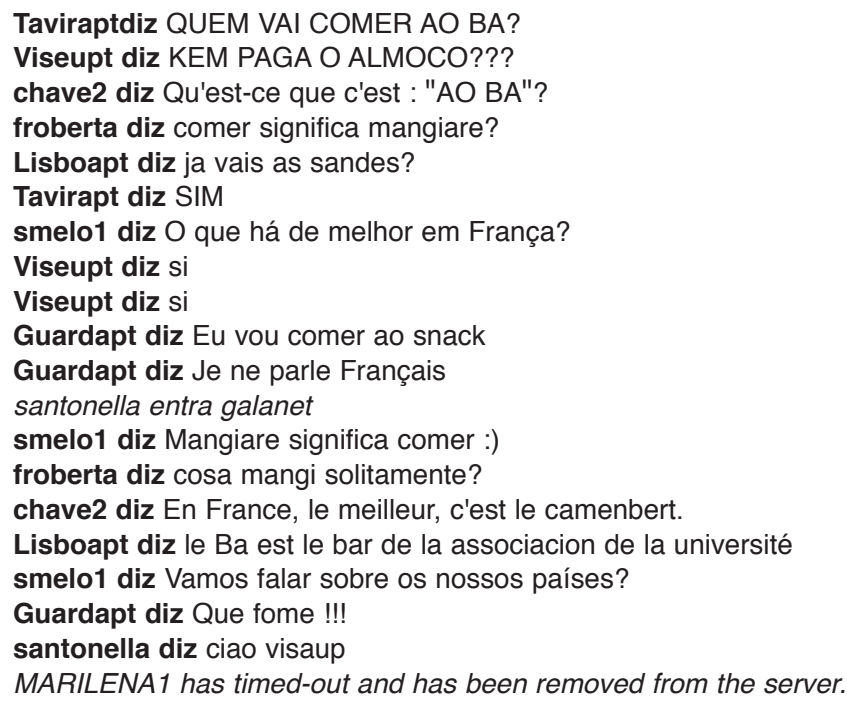

Do que atrás escrevemos e acima ilustrámos decorre a constatação de que o chat não deve ser considerado uma degeneração ou mistura de géneros já existentes (os géneros oral e escrito), mas antes a prova de que os indivíduos, em posse de novos recursos semióticos e comunicativos, atualizam e criam novos géneros discursivos, reveladores da riqueza criadora da linguagem e da criatividade dos seus utilizadores (as mesmas conclusões têm sido referidas em estudos sobre instrumentos como WhatsApp ou Twitter, 
para mencionar apenas dois). Claro que, como nota Mayans i Planells (2002), a comparação com géneros existentes e já estudados, como o oral e o escrito, potencia algumas abordagens e dela resultam analogias interessantes, mas não devemos prender as nossas análises a quadros interpretativos fixos. Pelas suas características peculiares, o chat deve ser considerado um género em si mesmo, com as suas particularidades. É também esta a opinião expressa por Araújo e Sá e Melo (2003b) quando, a propósito do uso de quadros de análise pré-existentes na análise das interações em chat, referem que

al mostrarse como tan radicalmente transgresores (a la luz, subrayamos, de la perspectiva ordenada de la interacción que nos facilitan los análisis lingüísticos), los chats muestran a las ciencias del lenguaje lo muy alejadas que éstas se encuentran de la realidad del trabajo lingüístico y cómo no poseen, por ahora, instrumentos heurísticos de análisis de ese trabajo, construyendo artefactos que sólo muy residualmente lo reflejan. (p. 49)

\section{Imagens e estereótipos na comunicação romanófona em chat: Entre facilidades, barreiras e utopias}

Propomos, no âmbito desta análise, evidenciar imagens e estereótipos face às línguas, às culturas, aos interlocutores e à situação de comunicação, por considerarmos que, enquanto elementos constitutivos do eu e enquanto construções sociais, esses elementos emergirão e serão negociados na interação, podendo, inclusive, tornar-se tópicos discursivos. Relembramos que esta situação de comunicação é caracterizada pela combinação das três características seguintes: a comunicação desenrola-se através de todo um aparato técnico - computador, ecrã, teclado, servidor, ... -, usa o chat enquanto instrumento de interação e desenvolve-se com o recurso simultâneo a várias LR.

O corpus no qual basearemos essa análise é constituído por duas sessões de chat plurilingue em LR (com a copresença de Português, Francês, Italiano e Espanhol), que ocorreram durante a fase inicial do projeto Galanet, com o objetivo de compreender a utilidade e rentabilidade didática da integração de funcionalidades de comunicação eletrónica na plataforma. Participaram alunos das diferentes instituições universitárias europeias parceiras do projeto (ver nota 2), a convite dos seus professores de disciplinas linguísticas (isto é, disciplinas relacionadas quer com o ensino-aprendizagem 
de LR específicas como línguas estrangeiras, quer com a sua didática). Os chats tiveram uma duração de cerca de 45 minutos cada, com um número de participantes variável, devido à natureza do instrumento de comunicação, que permite a entrada e saída de utilizadores. As sessões que são aqui objeto de análise contaram com a participação de quatro aprendentes lusófonos, três italófonos, quatro hispanófonos ${ }^{5}$ e três francófonos, bem como de quatro professores (um por cada grupo linguístico).

Os temas da conversação não tinham sido definidos à partida em nenhuma das sessões e os chatantes poderiam, por isso, determinar livremente e construir um percurso conversacional espontâneo. O nosso objetivo era observar a competência plurilingue em ação destes sujeitos romanófonos, nomeadamente ao nível da dimensão socioafetiva e, mais especificamente, a emergência de estereótipos e representações, conforme já referido. Os chats foram gravados, impressos e analisados enquanto produto de acontecimentos interacionais, sem, no entanto, se perder de vista as dinâmicas interacionais do chat enquanto processo. Com vista a facilitar a análise, foram selecionados episódios relevantes de emergência e negociação de imagens e representações em torno dos três polos anteriormente elencados: i) representações acerca das línguas e culturas; ii) representações acerca da interação plurilingue; e iii) representações acerca da comunicação em chat. A análise das sequências interacionais, que apresentamos de seguida, segue a mesma estruturação. O objetivo não será de analisar exaustivamente todo o corpus, mas antes ilustrar o potencial da emergência e negociação de imagens, isto é, da dimensão socioafetiva da CP, na coconstrução intersubjetiva da intercompreensão (aqui em LR).

\section{Representações acerca das línguas e culturas}

Observando as intervenções relativas a diferentes línguas, constatamos que, tratando-se de uma conversa que se desenrola em múltiplas línguas, essa diversidade é, de imediato, tomada como tema de conversa, seja pela enunciação das línguas que cada chatante conhece ("yo hablo bien el español [claro esta] el catalan [soy catalana] el ingles [lo que pasa es que hce mucho uqe no lo practico] y ahora un poco de francês"), seja pela curiosidade em relação às línguas conhecidas pelos outros ("che lingua parli?"), seja ainda pela comparação de diferentes itens linguísticos ("Beso em 
português diz-se Beijo... : *"). Neste sentido, estes chats plurilingues são um lugar de observação do "imaginário linguístico" dos participantes, isto é, do

rapport du sujet à la langue, la sienne et celle de la communauté qui l'intègre comme sujet parlant-sujet social ou dans laquelle il désire d'être intégré, par laquelle il désire être identifié par et dans la parole; rapport énonçable en termes d'images, participant des représentations sociales et subjectives, autrement dit d'une part des idéologies (versant social) et d'autre part des imaginaires (versant plus subjectif). (Houdebine-Gravaud, 2002, p. 10)

O carácter plurilingue das interações passa pela observação do funcionamento das diferentes línguas em presença e pelo seu uso por chatantes que não as têm como LM nem as reconhecem como línguas aprendidas ou dominadas. É este o caso de Guardapt, que afirma ter o Português como LM ("Guardaptdiz Sou Portugês de gema"), que, embora tenha aprendido Francês, não reconhece o seu estatuto de língua aprendida ("Guardaptdiz Je ne parle Français"), e que utiliza, por exemplo, um empréstimo do Italiano ("Guardaptdiz spageti??"), assinalando, deste modo, o seu comprometimento em relação à manutenção de um contrato de comunicação plurilingue.

Além disso, circulam na interação imagens que se (re)constroem acerca de diferentes línguas, deixando antever algumas representações em relação ao parentesco linguístico. Analisemos, num primeiro momento, dois exemplos 6 .

1)

smelo1 diz O Portuguiês é uma Língua difícil???

Nzinga diz Nao Smelo! Nao é uma lingua dificil!

2)

santonella diz tengo que marcharme, pero vuelvo pronto. Un beso

santonella diz como se dice beso en portugues?

chave2 diz Beijo

smelo1 diz Beso em português diz-se Beijo... : *

santonella diz que bonito. Me gustaria saber portugues...

smelo1 diz Português não é difícil, sobretudo para quem já sabe espanhol...

santonella diz estuve este verano en Porto y entendia casi todo

antonella diz hablar es un poco màs dificil...

smelo1 diz E há quem diga que o acento(sotaque) do Porto é difícil... 
santonella diz a mi me parecio bonito, casi tanto como la ciudad

smelo1 diz O Porto é mesmo muito bonito...

O primeiro exemplo remete para um estereótipo recorrente acerca das línguas: o seu grau de facilidade/dificuldade (vejam-se os estudos de Melo, 2006; Pinto, 2005; Schmidt \& Araújo e Sá, 2006, que ilustram a recorrência deste estereótipo particular a propósito de diferentes objetos linguísticos). É interessante verificar que o estereótipo "difícil" associado ao Português advém de um chatante lusófono (autoestereótipo) e é contrariado por um francófono (heteroestereótipo), mostrando que a interação plurilingue é um lugar privilegiado de observação das imagens e dos estereótipos acerca das línguas, dando conta, como antes afirmámos, dos "imaginários linguísticos" dos participantes.

O segundo exemplo refere-se ainda à língua portuguesa e remete para dois aspetos em concreto: a suposta facilidade de intercompreensão entre o Português e o Espanhol, devido à proximidade tipológica, revelada sobretudo ao nível da compreensão por oposição à expressão; e a dificuldade que um sotaque particular (o do Porto) pode colocar ao nível da compreensão. De notar, mais uma vez, que o estereótipo da dificuldade é veiculado novamente pelo chatante nativo de Português, que o generaliza num comum "há quem diga" ("E há quem diga que o acento (sotaque) do Porto é difícil..."), sendo rebatido pelo chatante hispanófono ("a mi me parecio bonito, casi tanto como la ciudad"). Refira-se ainda que, ao contrário do que acontece no primeiro exemplo, os chatantes encontram um referente de consenso (a beleza da cidade do Porto), que conclui a troca acerca da língua portuguesa e que funciona, na nossa opinião, como lugar de mediação em relação a essa língua e ao sotaque particular do Porto, e como lugar de partilha de experiências vividas, trazendo à sequência um "desfecho feliz".

Se nos debruçarmos, agora, exclusivamente, sobre o campo das manifestações interativas referentes às culturas românicas, observa-se, nas interações em foco, a vontade de conhecer as outras culturas ("csilvia1diz guardapt como es il portogallo?", "Cassino1diz COME SONO GLI OVOS MOLES?") e, ao mesmo tempo, de se dar a conhecer ("Guardaptdiz vinho do Porto, muito bom", "smelo1diz Em POrtugal, o melhor é o Cozidoà Portuguesa..."), num movimento dialético de abertura entre o "eu" e o "outro". Simultaneamente, parece emergir um desejo de aceitação e até de avaliação 
da própria cultura pelo outro ("csilvia1diz guardapt ti piace l'italia e il calcio italiano?", "csilvia1diz nzinga ti piace l'italia?", "frobertadiz cosa pensate delle ragazze italiane?"), numa clara perspetiva de relativização cultural e de reconhecimento que a construção e aceitação da imagem de si mesmo passa pela imagem que o "outro" construiu e manifestou através da interação, como que pretendendo mostrar que através de um esforço comparativo se ganhará em auto e heteroconhecimento. Na verdade, enquanto elementos de construção da própria identidade e de sociabilidade, "stereotypes . . reveal how a group perceives its own identity, and demonstrate its cohesion. They provide a framework for interpretation, through comparisons and contrasts with characteristics attributed to other groups" (Castellotti \& Moore, 2002, p. 8).

\section{Representações acerca da comunicação plurilingue}

Tomemos agora como referência dois outros exemplos, reveladores de imagens acerca da comunicação plurilingue e da intercompreensão entre línguas da mesma família:

3)

Barcelone diz es interensante ver tantos idiomas...

francesca_it diz barcelone che cosa studi?

Bragapt diz barcelone: tu parlas portugais

Barcelone diz no, no habla nada de portugues, pero se puede entender bastante bien ( añadiendole un poco de imaginacion, claro)

francesca_it diz quali linghe parli, Barcelona?

Bragaptdiz nos estudamos linguas

Barcelone diz yo hablo bien el español (claro esta) el catalan (soy catalana) el ingles (lo que pasa es que hce mucho uqe no lo practico) y ahora un poco de frances

4)

Lagosptdiz Parece que o tema das cidades se perdeu... E o do futebol também... De que estamos afalar agora? ESTOU PERDIDA:......:.

azucenanovoy diz Hablamos de las lenguas latinas

azucenanovoy diz y de como podemos entendernos hablando cada uno en su idioma

Lagospt diz Eu falo Português que é muito parecedo com o Espanhol e com as restantes Línguas Românicas... Assim entendemo-nos bem e não 
precisammos de recorrer a uma língua comum a todos...;

Bragapt diz acho que ate agora nos estamos a entender muito bem

Lagospt diz E nem precisamos de nos ver para nos entendermos, não é?

azucenanovoy diz Tenés razon Lagospt

Lagospt diz Queria falar mais línguas, para ficar mais perto de todos...

azucenanovoy diz $\mathrm{Y}$ entonces porque tendemos a usar otra lengua para comunicarnos, quiero decir una tercera como ...el inglés por ejemplo. Piendso en argentinos hablando inglés en Paris.

O exemplo 3 volta a focar o papel da proximidade linguística na intercompreensão entre falantes de diferentes LR, nomeadamente através do que nos parece ser uma representação acerca das possibilidades de estabelecer passerelles interlinguísticas ("se puede entender bastante bien, añadiendole un poco de imaginacion, claro"). O quarto exemplo, na sequência do que acabámos de dizer, foca a "felicidade" sentida pelos chatantes que advém da possibilidade de recurso a diferentes LM na comunicação exolingue, evitando o recurso a uma língua franca ("Piendso en argentinos hablando inglés en Paris"), sem prejuízo para a intercompreensão: "Assim entendemo-nos bem e não precisammos de recorrer a uma língua comum a todos..., acho que ate agora nos estamos a entender muito bem e Tenés razon Lagospt". De notar que uma intervenção que se situa anteriormente no nosso corpus remete para o facto de haver um acordo implícito de intercompreensão plurilingue e de os interlocutores compreenderem e tentarem cumprir esse acordo ("Lagosptdiz Não vamos confundir os idiomas... Só é preciso perceber..."), como se de um contrato didático se tratasse.

Estes dois exemplos remetem-nos, claramente, para o "bonheur conversationnel" (ver acima) que caracteriza as interações plurilingues que recolhemos. Na verdade, é aqui visível "un état émotionnel de base qui soustend l'interaction et qui, dans cette situation, semble être positif, tout en les poussant à participer à l'interaction" (Araújo e Sá \& Melo, 2003a, p. 105), nomeadamente em situações de resolução de problemas comunicativos decorrentes de incompreensão dos códigos linguístico-verbais, de explicitação de competências linguísticas e de justificação do sucesso comunicativo. Por outro lado, não deixa de ser visível uma certa emoção ("francesca_itdiz tante lingue!!") que advém da observação e experimentação desse sucesso ("es interensante ver tantos idiomas...") e o desejo de atualizar os conhecimentos linguísticos como forma de (re)encontro com a alteridade ("lagospt diz Queria falar mais línguas, para ficar mais perto de todos..."). 
Não se pense, contudo, que apenas encontramos nas intervenções dos chatantes manifestações marcadoras de agrado face à diversidade das línguas em contacto. $\mathrm{Na}$ verdade, alguns interlocutores manifestam dificuldades de relacionamento em e com algumas LE ("francesca_itdiz non capisco colômbia" e "frobertadiz scusate la mia ignoranza sulla vostra lingua, ma a me piace il francese"7, respetivamente), sugerindo o recurso a uma língua franca, com o objetivo pragmático/utilitário de facilitar a comunicação (ou diremos: de evitar a interincompreensão?) e, desse modo, de assegurar a intercompreensão: "csilvia1diz tavirapt parli inglese?", "csilvia1diz guardapt non capisco molto della tua lingua parli inglese?"8. Podemos, de acordo com intervenções que considerámos exemplificativas, tentar descortinar as eventuais barreiras ao contacto com algumas das línguas: pensamos, por exemplo, em intervenções que remetem para o monolinguismo dos chatantes ("francesca_itdiz parlo solo italiano"), para o desconhecimento de algumas línguas em particular ("Aveiroptdiz francesca que estas parlando?? no cappisco niente!!!!") e para uma imagem negativa das próprias competências em LE ("Guardaptdiz Je ne parle Français"). Todavia, mesmo nestes casos, notamos alguns movimentos de aproximação às línguas que se julgam desconhecer: veja-se que os chatantes Aveiropt e Guardapt manifestam o seu desconhecimento em relação às línguas italiana e francesa, respetivamente, recorrendo a elas, revelando dificuldades de compreensão e/ou de expressão nessas línguas, mas evidenciando um forte desejo de ser compreendidos pelos interlocutores italófonos e francófonos.

\section{Representações acerca da comunicação em chat}

Terminemos esta análise com uma breve referência à forma como os chatantes percecionam a comunicação em chat. Em primeiro lugar, surgem referências ao suporte técnico, mas apenas em situações em que o seu manuseamento bloqueia a comunicação (diríamos que o computador só parece ter visibilidade quando coloca problemas): "francesca_itdiz si è bloccato il computer", "azucenanovoydiz Disculpen las limitaciones que me impone el teclado francês" e "Lagosptdiz Parece que tive um problema com o servidor!!!".

Em contrapartida, encontramos um grande número de manifestações socioafetivas em relação à comunicação plurilingue e ao facto de ela se 
desenrolar através de chat: "Lisboaptdiz a todos os portugueses em linha OLA!!!!!!!!!!!!", "colombiadiz bueno fue un placer muy grande / compartir con ustedes una hora de mi vida", "Viseuptdiz ragazzos italianos onde estão??????????". Estas manifestações de adesão afetiva ao instrumento de comunicação são ainda visíveis quando os chatantes transformam características do chat em objetos de conversação. Assim, encontramos referências ao facto de se tratar de uma conversa virtual ("chave2diz A bientôt, je retourne dans la vraie vie"), à opacidade identitária e à possibilidade de a tomar como objeto discursivo ("smelo1diz Ninguém sabe o que os nicks portugueses significam????", "colombiadiz soy solo un pseudónimo", "Cassino1diz bonjour a tout le monde. J'ai le meme peseudo mais je suis un étudiant different... ", "Cassino1diz attention j'ai change d'identite (de nouveau!) maintenant je suis une etudiante de Cassino et je parle italien"), ao facto de admitir um número variável de intervenientes de diversas proveniências geográficas e temporais ("frobertadiz ciao caro francese" e "PibedesAlpesdiz tout le monde s'en va quand j'arrive. Snif!!! je me suis trompé d'heure?") e, por último, à possibilidade de teatralizar as identidades e as ações, devido à opacidade contextual que o meio possibilita ("Guardaptdiz eu não sou espanhol, mas tenho muita imaginação", "Lagosptdiz Antonelo, pagas a pizza????" e "colombiadiz aveiro comparto contigo el pollo, te doy las plumas").

Fica assim claro que os intervenientes não são ingénuos quanto ao uso que fazem dos meios linguísticos e tecnológicos ao seu alcance, tomando-os como objetos do discurso, problematizando-os e rentabilizando o seu uso na comunicação, num contrato didático implícito de busca da intercompreensão, utopia última.

\section{Síntese e conclusões}

Como previsível pela própria natureza da situação de comunicação analisada, encontrámos, no nosso corpus, exemplos de mobilização de auto e heteroimagens e estereótipos em relação às línguas, aos interlocutores e à diversidade linguística e cultural, bem como de representações acerca do uso dos chats. Conforme tínhamos adiantado, essas imagens e estereótipos são indissociáveis das características intrínsecas desta interação - endolingue, exolingue ou plurilingue - e acabam por se manifestar, mais ou menos 
assiduamente, com maior ou menor veemência, ao longo de várias sequências interacionais. Deste modo, poderíamos afirmar que as imagens e estereótipos não são apenas um déjà-là da situação comunicativa, tornandose temas conversacionais, prontamente abraçados pelos participantes. $\mathrm{Na}$ verdade, conforme demos conta noutro estudo, a negociação colaborativa de estereótipos e representações (designadamente sobre línguas e os seus falantes) são um dos temas mais recorrentes na comunicação plurilingue (Melo, 2006). A sua emergência e negociação discursiva estão na origem de extensas sequências conversacionais, quer de reforço, quer de refutação do seu conteúdo semântico, o que mostra o potencial comunicativo (e intercultural) de os mobilizar, discutir, desconstruir e reconstruir.

$\mathrm{Na}$ verdade, as imagens das línguas, culturas e situações de comunicação, constructos conscientes ou inconscientes, provenientes de contactos reais ou não, ajudam a definir e condicionam os comportamentos e as interações (cf. Simões \& Araújo e Sá, 2004, p. 285) e, nesse sentido, a sua observação é um elemento crucial em Didática de Línguas para planificar a ação educativa. Nas interações que analisámos, ao mostrarem as predisposições/aberturas socioafetivas dos interlocutores e emergindo como variável lúdica da situação comunicativa, as imagens e estereótipos funcionaram como tópicos discursivos e como "desbloqueadores de conversa" (propulsionando a interação plurilingue), revelaram-se importantes fatores de coesão e de colaboração entre os chatantes e concorreram para o bem-estar comunicativo e para a coconstrução da "felicidade" comunicativa e da intercompreensão. Podemos assim concluir que esta situação comunicativa mostra potencialidades que podem ser exploradas no sentido de uma educação para a diversidade linguística e cultural que promova a aproximação a diferentes línguas e culturas (aqui, românicas) e a capacidade e vontade de as utilizar.

\section{Notas}

1 O presente texto retoma e alarga o estudo publicado em Araújo e Sá e Melo (2004).

2 A "GALANET: plataforma para o desenvolvimento da intercompreensão em línguas românicas" foi desenvolvida no âmbito de um projeto Sócrates/LINGUA 2001-2004), coordenado pela Université Stendhal-Grenoble 3 (França), que contou com seis 
outras instituições parceiras: Universidade de Aveiro (Portugal), Universitat Autònoma de Barcelona (Espanha), Universidad Complutense de Madrid (Espanha), Università de Cassino (Itália), Université Lumière-Lyon 2 (França) e Université de Mons-Hainault (Bélgica). Este grupo de parceiros esteve envolvido, posteriormente, em mais dois projetos europeus sobre intercompreensão em línguas românicas: Galapro (coordenado por Maria Helena Araújo e Sá, http://galapro.miriadi.net/sessions/) e Miriadi (coordenado por Sandra Garbarino, http://miriadi.net/elgg/miriadi/home). A plataforma Galanet encontra-se atualmente desativada, por questões relacionadas com a evolução tecnológica, ocorrendo as sessões de formação na plataforma Miriadi (https://www.miriadi.net/formation).

3 Tomamos aqui o conceito de "modelo cultural" de Schütz (1987, p. 218, citado por Oesch-Serra, 1995): "toutes les valeurs spécifiques, les systèmes d'orientation et de conduite (comme le folklore, les mœurs, les lois, les habitudes, les coutumes, l'étiquette, les modes) qui... caractérisent - voire constituent - tout groupe social à un moment donné de son histoire" (p. 16).

4 Este exemplo foi transcrito com a ortografia original e sem qualquer corte, para melhor ilustrar o que até aqui fomos argumentando.

5 Os estudantes catalães participantes comunicaram em Espanhol.

6 Todos os exemplos são reproduzidos com a ortografia original mas foram cortados, de forma a evidenciar os objetos de análise.

7 Intervenção de uma chatante italófona a propósito do Português e do Francês.

8 Ambos os exemplos são de chatantes italófonos que se referem ao Português.

\section{Referências}

Alarcão, I., Andrade, A. I., Araújo e Sá, M. H., Melo-Pfeifer, S., \& Santos, L. (2009). Intercompréhension et plurilinguisme : $(\mathrm{Re})$ configurateurs épistémologiques d'une Didactique des Langues?. ELA, 153, 11-24.

Amossy, R., \& Herscheberg Pierrot, A. (1997). Stéréotypes et clichés. Paris: Nathan Université Ed.

Andrade, A. I., \& Araújo e Sá, M. H., Bartolomeu, I., Martins, F., Melo, S., Santos, L., \& Simões, A. R. (2003). Análise e construção da competência plurilingue - Alguns percursos didácticos. In A. Neto, J. Nico, J. C. Chouriço, P. Costa, \& P. Mendes (Orgs.), Didácticas e metodologias de educação - Percursos e desafios (pp. 489-506). Évora: Departamento de Pedagogia e Educação da Universidade de Évora.

Araújo e Sá, M. H. (2013). A intercompreensão em Didática de Línguas: Modulações em torno de uma abordagem interacional. Linguarum Arena, 4, 79-106.

Araújo e Sá, M. H., \& Melo, S. (2003a). "Beso em português diz-se beijo :*" : La gestion des problèmes de l'interaction dans des chats plurilingues romanophones. Lidil, 28, 95-108. 
Araújo e Sá, M. H., \& Melo, S. (2003b). Del caos a la creatividad: Los chats entre lingüistas y didactas. In C. Alonso \& A. Séré (Dirs.), Los textos electrónicos: Nuevos géneros discursivos (pp. 45-61). Madrid: Biblioteca Nueva.

Araújo e Sá, M. H., \& Melo, S. (2004). Entre o "no capisco niente!!!!" e o "es interesante ver tantos idiomas..." - Imagens e estereótipos na comunicação romanófona em chat. In M. H. Araújo e Sá \& S. Melo, Intercompreensão em situação de chat romanófono: Um módulo de formação (pp. 118-129). Aveiro: CIDTFF, Universidade de Aveiro.

Auchlin, A. (1995). Le bonheur conversationnel: Émotion et cognition dans le discours et l'analyse du discours. In D. Véronique \& R. Vion (Eds.), Modèles de I'interaction verbale (pp. 224-233). Aix-en-Provence: Publications de l'Université de Provence.

Beacco, J. C. (2013). Éthique et politique en didactique des langues. Autour de la notion de responsabilité. Paris: Didier.

Bono, M., \& Melo-Pfeifer, S. (2011). Language negotiation in multilingual learning environments. International Journal of Bilingualism, 15(3), 291-309.

Castellotti, V., \& Moore, D. (2002). Social representations of languages and teaching Reference study for the guide for the development of language education policies in Europe - From linguistic diversity to plurilingual education. Strasbourg: Council of Europe.

Conselho da Europa (2001). Quadro Europeu Comum de Referência para as Línguas Aprendizagem, ensino, avaliação. Porto: Edições Asa.

Houdebine-Gravaud, A. M. (2002). L'imaginaire linguistique: Un niveau d'analyse et un point de vue théorique. In A. M. Houdebine-Gravaud (Dir.), L'imaginaire linguistique (pp. 9-21). Paris: L'Harmattan.

Jodelet, D. (1989). Les représentations sociales : Un domaine en expansion. In D. Jodelet (Dir.), Les représentations sociales (pp. 45-78). Paris: P.U.F.

Lüdi, G. (2004). Pour une linguistique de la compétence du locuteur plurilingue. Revue Française de Linguistique Appliquée, ix(2), 125-135.

Lüdi, G. (Ed.). (1987). Devenir bilingue, parler bilingue. Tübingen: Niemayer.

Lüdi, G., \& Py, B. (1986). Être bilingue. Berne: Peter Lang.

Mayans i Planells, J. (2002). Genero chat o cómo la etnografía puso un pie en el ciberespacio. Barcelona: Editorial Gedisa.

Melo, S. (2006). Emergência e negociação de imagens das línguas em encontros interculturais plurilingues em chat (Tese de Doutoramento). Universidade de Aveiro, Aveiro.

Melo-Pfeifer, S., \& Araújo e Sá, M. H. (Eds.). (2013). Comunicação eletrónica na aula de Português Língua Estrangeira. Lisboa: Lidel.

Morala, J. (2001, outubro). Entre arrobas, eñes y emoticones. Apresentação no II Congresso da Língua Espanhola, Valladolid. https://cvc.cervantes.es/obref/ congresos/valladolid/ponencias/nuevas_ fronteras_del_espanol/ 4_lengua_y_ escritura/morala_j.htm 
Oesch-Serra, C. (1995). L'évolution des représentations. In G. Lüdi \& B. Py (Eds.), Changement de langage et langage du changement : Aspects linguistiques de la migration interne en Suisse (pp. 147-170). Lausanne: Editions L'Age d'Homme.

Parlamento Europeu (2000). Linguistic diversity on the Internet: Assessment of the contribution of machine translation. Disponivel em: http://www.europarl. europa.eu/thinktank/fr/document.html?reference=DG-4-JOIN_ET(2000)289662

Pimienta, D. (2002, novembro). Presencia de las lenguas neolatinas en la Internet. Comunicação apresentada no Congrès International sur les langues néo-latines dans la communication spécialisée, Cidade do México.

Pinto, S. (2005). Imagens das línguas estrangeiras de alunos universitários portugueses (Dissertação de Mestrado). Universidade de Aveiro, Aveiro.

Py, B. (1994). Le parler bilingue. In C. Allemann-Ghionda (Dir.), Multiculture et éducation en Europe (pp. 105-112). Berne: Peter Lang.

Schmidt, A., \& Araújo e Sá, M. H. (2006). "Difícil, feia e esquisita": A cristalização de um discurso escolar sobre o alemão. In A. I. Andrade \& M. H. Araújo e Sá (Coords.), Imagens das línguas em contextos de educação e formação linguística (pp. 922). Aveiro: CIDTFF, Universidade de Aveiro.

Simões, A. R., \& Araújo e Sá, M. H. (2004). "Aquele de camisas às flores é brasileiro": Estereótipos sobre línguas e povos manifestados por alunos do $3^{\circ}$ Ciclo do Ensino Básico. In A. D. Barker (Ed.), O poder e a persistência dos estereótipos (pp. 283-297). Aveiro: Universidade de Aveiro, Departamento de Línguas e Culturas.

Tudini, V. (2002). The role of on-line chatting in the development of competence in oral interaction. In Kennedy, C. (Ed.), Proceedings of Innovations in Italian Teaching Workshop (pp. 40-57). Griffith University. Disponível em: http://docplayer.net/ 47670056-Proceedings-of-innovations-in-italian-teaching-workshop-griffithuniversity-vincenza-tudini-pages-40-57.html

Tudini, V. (2003). Éléments conversationnels du clavardage : Un entraînement à l'expression orale pour les apprenants de langues à distance?. Alsic [En ligne] - Apprentissage des Langues et Systèmes d'Information et de Communication, 6(2), 63-81. http://alsic.revues.org/2231

Yus, F. (2001). Ciberpragmática. El uso del lenguaje en Internet. Barcelona: Ariel Lingüística. 
THE AFFECTIVE DIMENSION IN PLURILINGUAL INTERACTION: DYNAMICS IN NEGOTIATING IMAGES AND STEREOTYPES IN CHAT INTERACTION WITH ROMANCE LANGUAGES

\section{Abstract}

Given the importance of the Internet as a contact tool at an intercultural and multilingual level, and considering a definition of communication spaces as places where images about the Other emerge and are negotiated, we will analyze a corpus of plurilingual interactions in chat conversations (in Romance Languages), in order to study the dynamics of the images and stereotypes in this communication situation. We will attempt to uncover barriers to intercultural communication, expose some utopias about it (like the use of a lingua franca as a solution to communication problems) and discover the possibilities propelling interaction, such as an affective relationship with the languages, the speakers and the communication situation. Data discussion will allow us to demonstrate how crossed images and stereotypes of the speakers towards others, their languages and cultures emerge in the interaction, how they feed and stimulate conversation and how they trigger 'happy' moments of plurilingual communication.

Keywords

Electronic communication; Intercomprehension; Images; Stereotypes

\section{LA DIMENSION AFFECTIVE DANS L'INTERACTION PLURILINGUE : DYNAMIQUES DE NÉGOTIATION D'IMAGES ET STÉRÉOTYPES DANS L'INTERACTION ROMANOPHONE PAR CLAVARDAGE}

\section{Résumé}

Sachant que I'Internet joue un rôle fondamental dans le contact interculturel et plurilingue et que les espaces de communication sont des contextes d'émergence et de négociation d'images sur l'Autre, on analysera un corpus 
constitué par des interactions plurilingues romanophones en chat, afin d'étudier la dynamique des images et des stéréotypes dans cette situation de communication. On essayera de dégager des barrières à la communication interculturelle, quelques utopies à son égard (particulièrement, le recours à une lingua franca comme solution aux problèmes communicatifs) et des aspects capables d'encourager l'interaction, tels que la relation affective avec les langues, les locuteurs et la situation de communication. L'analyse mettra en évidence comment les images et les stéréotypes croisés des locuteurs les uns envers les autres, leurs langues et leurs cultures surgissent dans l'interaction, comment ils stimulent et "nourrissent" la conversation et provoquent des moments "heureux" de communication plurilingue.

Mots-clé

Communication électronique ; Intercompréhension ; Images ; Stéréotypes

Recebido em abril 2017 Aceite para publicação em setembro 2017

i Faculty of Education, University of Hamburg, Germany \& Centro de Investigação em Didática e Tecnologia na Formação de Formadores (CIDTFF), Universidade de Aveiro, Portugal.

ii Departamento de Educação e Psicologia \& Centro de Investigação em Didática e Tecnologia na Formação de Formadores (CIDTFF), Universidade de Aveiro, Portugal.

Toda a correspondência relativa a este artigo deve ser enviada para: Maria Helena Araújo e Sá, Departamento de Educação e Psicologia (DEP), Universidade de Aveiro, Campus Universitário de Santiago, 3810-193 Aveiro, Portugal. E-mail: helenasa@ua.pt 